\title{
Brief Communication:
}

\section{"An inventory of permafrost evidence for the European Alps"}

\author{
E. Cremonese ${ }^{1}$, S. Gruber ${ }^{2}$, M. Phillips ${ }^{3}$, P. Pogliotti ${ }^{1}$, L. Boeckli ${ }^{2}$, J. Noetzli ${ }^{2}$, C. Suter ${ }^{3}$, X. Bodin ${ }^{4}$, A. Crepaz $^{5}$, \\ A. Kellerer-Pirklbauer ${ }^{6,7}$, K. Lang $^{8}$, S. Letey ${ }^{1}$, V. Mair ${ }^{8}$, U. Morra di Cella ${ }^{1}$, L. Ravanel ${ }^{4}$, C. Scapozza ${ }^{9}$, R. Seppi ${ }^{10}$, \\ and A. Zischg ${ }^{11}$ \\ ${ }^{1}$ Environmental Protection Agency of Aosta Valley, ARPA Valle d'Aosta, Saint Christophe, Italy \\ ${ }^{2}$ Glaciology, Geomorphodynamics and Geochronology, Department of Geography, University of Zurich, Zurich, Switzerland \\ ${ }^{3}$ WSL Institute for Snow and Avalanche Research SLF, Davos, Switzerland \\ ${ }^{4}$ Laboratoire EDYTEM, CNRS, Université de Savoie, Le Bourget du Lac, France \\ ${ }^{5}$ Arabba Avalanche Center, Environmental Protection Agency of Veneto, ARPAV, Arabba di Livinallongo, Italy \\ ${ }^{6}$ Department of Geography and Regional Science, University of Graz, Graz, Austria \\ ${ }^{7}$ Institute of Remote Sensing and Photogrammetry, Graz University of Technology, Graz, Austria \\ ${ }^{8}$ Autonomous Province of Bolzano, Geological Service, Bolzano, Italy \\ ${ }^{9}$ Institute of Geography, University of Lausanne, Lausanne, Switzerland \\ ${ }^{10}$ Earth Science Department, University of Pavia, Pavia, Italy \\ ${ }^{11}$ Abenis Alpinexpert Srl, Bozen/Bolzano, Italy
}

Received: 28 March 2011 - Published in The Cryosphere Discuss.: 18 April 2011

Revised: 3 August 2011 - Accepted: 4 August 2011 - Published: 22 August 2011

\begin{abstract}
The investigation and modelling of permafrost distribution, particularly in areas of discontinuous permafrost, is challenging due to spatial heterogeneity, remoteness of measurement sites and data scarcity. We have designed a strategy for standardizing different local data sets containing evidence of the presence or absence of permafrost into an inventory for the entire European Alps. With this brief communication, we present the structure and contents of this inventory. This collection of permafrost evidence not only highlights existing data and allows new analyses based on larger data sets, but also provides complementary information for an improved interpretation of monitoring results.
\end{abstract}

\section{Introduction}

In mountain areas, permafrost distribution is spatially heterogeneous and there is a scarcity of direct permafrost measurements and observations. In the European Alps, numerous local permafrost distribution models have been devel-

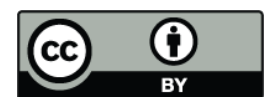

Correspondence to: E. Cremonese (e.cremonese@arpa.vda.it) oped (e.g. Keller, 1992; Hoelzle, 1996; Imhof, 1996; Gruber and Hoelzle, 2001; Lambiel and Reynard, 2001), but are usually based on a small number of data points (often proxies) from rather restricted regions. Similarly, statistical analyses of permafrost distribution patterns taking into account topography, mean annual air temperature (MAAT) or precipitation face the challenge of assembling heterogeneous data. In order to make the most of the potential of existing data, an Alpine-wide standardized collection of permafrost evidence has been carried out and is described here. We define a permafrost evidence to be a point or an area where permafrost is known to be present during a certain time or where the absence of permafrost can be ascertained. The wide variety of relevant field measurements and observations (e.g. temperature in boreholes or near the ground surface, rock glacier mapping, geophysics), and their different spatial scale of reference, make the process of data standardization challenging. Permafrost experts from several European Alpine countries have contributed to the inventory presented here (Appendix B). It was compiled within the framework of the project PermaNET and combines results obtained by many researchers and data assembled by national or regional monitoring programmes such as PERMOS (Noetzli and Vonder Muehll, 2010), PermaFRANCE (Schoeneich et al., 2010)

Published by Copernicus Publications on behalf of the European Geosciences Union. 
or PROALP (Mair et al., 2008). With this brief communication we aim to present the first version of the concept, structure and data of the inventory. In addition, we hope this brief communication will also contribute to the further improvement of the inventory through peer-review, to widen its usage and to improve its integration in the context of national and international monitoring and measurement programs.

\section{Structure and organization of the inventory}

The design and implementation of the inventory is based on the following principles: the inventory has to be simple in structure and technical implementation and the number of parameters must be kept small. This allows researchers to register their existing data within the newly standardized scheme in a user-friendly manner. For important variables, at least a qualitative uncertainty is assigned. After insertion, data are verified in order to remove obvious errors. Basic information on the origin of each evidence point is required, such as a published reference or the measurement method applied. The inventory contains the following types of evidence: borehole temperature $(\mathrm{BH})$, ground surface temperature (GST), rock fall scar (SC), trench or construction site (TR), surface movement (SM), geophysical prospecting (GP), other indirect evidence (OIE) and rock glaciers (RG). SC and TR are considered to be evidence of permafrost only if ice has been seen (e.g. on photographs or in-situ) and can be excluded to be seasonal. The criterion to exclude seasonal ice is a depth exceeding five meters from the surface. SM is usually based on field observations, terrestrial surveys, photogrammetric analyses or DInSAR data. GP include primarily geoelectrics, seismics, ground penetrating radar and electromagnetic prospecting. OIE provides room for further types of evidence such as thermokarst depressions.

For all types of evidence, general information concerning for example location and the person responsible are required. Additionally, contributors can use the optional fields available for comments and further specification of criteria. BH, GST and SM have additional specific data fields. The complete list and description of information contained in the inventory are presented in Appendix A.

The rock glacier inventory ( $R G)$ is managed separately from the point types of evidence. Individual RG inventories are supplied as a collection of polygons and/or centroids (shapefiles) in local coordinate systems and then transformed to the common coordinate system WGS84. The contribution of an inventory requires the addition of common data fields into the GIS attribute table and supplying separate metainformation about the inventory. The estimation of RG activity is based on field observation or image interpretation (e.g. aerial photography, satellite imagery) of typical morphological characteristics (e.g. steepness of the front, absence of vegetation) and then classified as being "intact" (i.e. active or inactive landform with permafrost) or "relict" (i.e. without permafrost) and minimal information explaining the grounds for this assessment is included (Appendix A).

\section{Data collection, verification and homogenization}

The inventory was completed using four "calls for evidence" accompanied by a spreadsheet and detailed instructions. Thirty-five individuals or institutions provided data. Contributors provided information from their own research areas, consisting of existing data and knowledge adapted to the common data format used in this inventory. This was complemented by specific investigations in collaboration with regional/local geological services, ski resort operators, engineering companies or alpine guide societies. The design and administration of the inventory was carried out jointly by ARPA Valle d'Aosta (Italy), the WSL Institute for Snow and Avalanche Research SLF and the Department of Geography of the University of Zurich (Switzerland).

To avoid errors in spatial positioning introduced during data entry or coordinate transformation, the assembled inventory was sent as a KML file to all contributors for visual verification of the provided information using Google Earth. An updated version of the inventory was released using the feedback from the contributors after verification.

As the dataset is characterized by a high degree of heterogeneity, the issue of data homogenization is very important and still under development. A first step towards homogenization has been made for GST data measured on steep rock walls: as their inter-annual variation is similar to that of MAAT, a normalization procedure (Allen et al., 2009) to estimate mean annual ground surface temperature (MAGST) for the period 1961-1990 has been applied to make measurements from differing years comparable. Based on the resulting temperatures and considering possible mechanisms of thermal offset, GST points were classified into the categories "presence" or "absence" of permafrost with differing degrees of certainty (permafrost presence: MAGST $<-2{ }^{\circ} \mathrm{C}$ medium certainty; $-2{ }^{\circ} \mathrm{C}<$ MAGST $<0^{\circ} \mathrm{C}$ low certainty; permafrost absence: $0{ }^{\circ} \mathrm{C}<$ MAGST $<2{ }^{\circ} \mathrm{C}$ low certainty; MAGST $>2{ }^{\circ} \mathrm{C}$ medium certainty).

\section{Content of the inventory}

The total number of point type permafrost evidence is 408 (October 2010), extending from 44.29 to $47.47^{\circ} \mathrm{N}$ and from 5.91 to $14.88^{\circ} \mathrm{E}$ and covering all Alpine countries except Monaco, Liechtenstein and Slovenia. The rock glacier dataset includes seven inventories from Italy, Austria, Switzerland and France with a total of 4795 rock glaciers (Fig. 1). The seven inventories are regional (Valle d'Aosta, Piemonte, Veneto, Trentino Alto Adige in Italy, Massif du Combeynot in France, Ticino in Switzerland and central and eastern Austria) and thus do not cover the entire European Alps. 


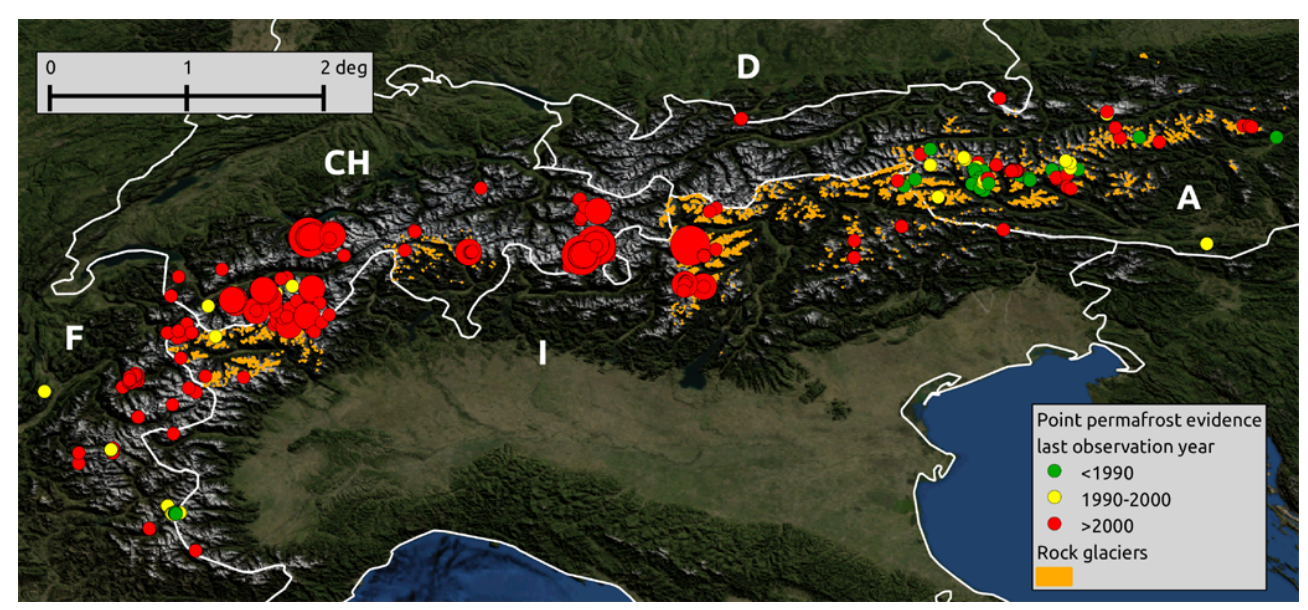

Fig. 1. Map of the permafrost evidence acquired in the Alps. The dots represent point permafrost evidence. The colors of dots represent the classes of last observation dates confirming permafrost state (before 1990, between 1900 and 2000, after 2000). The size of the dots indicates 3 classes $(<3 \mathrm{yr}, 3-8 \mathrm{yr},>8 \mathrm{yr})$ representing the length of observations/measured data associated with each evidence. Orange polygons represent rock glacier inventories.

a)

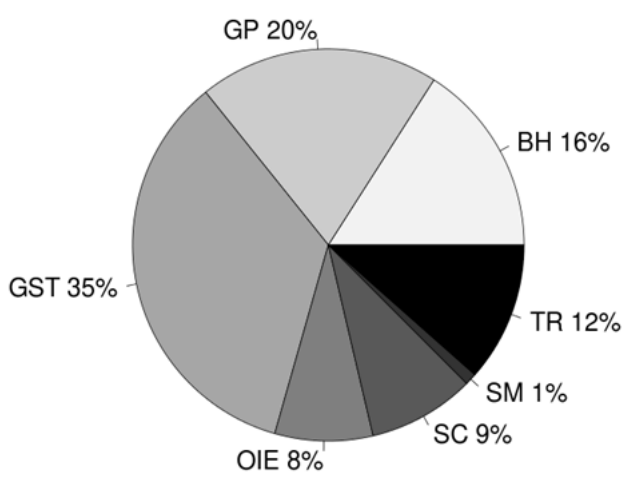

b)

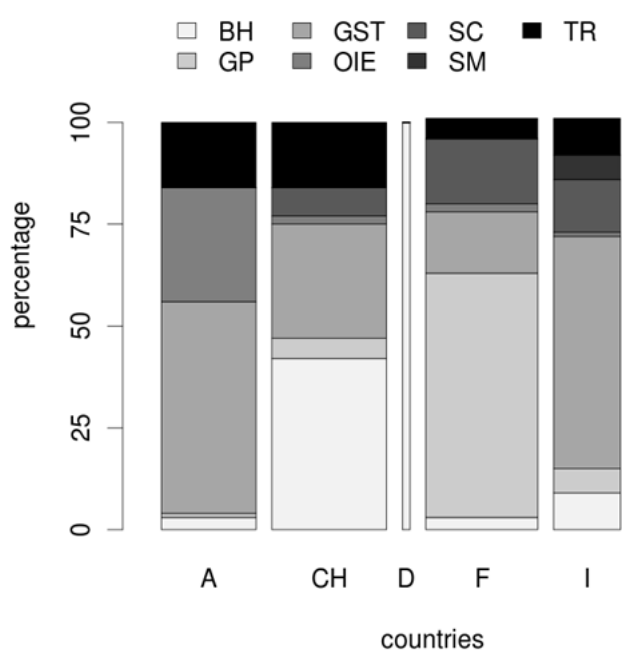

Fig. 2. (a) Relative amounts of point evidence types (borehole (BH), geophysical prospecting (GP), ground surface temperature (GST), other indirect evidence (OIE), rock fall scar (SC), surface movement (SM), trench or construction site (TR)) in the entire inventory and (b) by country. Bar width represents the relative abundance of evidence in each country: A-24\%, CH-29\%, D- $0.5 \%$, F-28 \%, I- $17 \%$; for graphical reasons, Germany bar width has been increased (tripled).

GST, BH and GP are the most common types of point evidence. Most of the points are located in Switzerland, France and Italy (Fig. 2). The elevation of the permafrost evidence ranges from $1000 \mathrm{~m}$ a.s.l. in a cold talus slope in central Austria (Toteisboden) to $4120 \mathrm{~m}$ a.s.l. for a GST point in the Mont Blanc Massif (Grandes Jorasses); however, the majority $(>60 \%)$ are situated between 2500 and $3000 \mathrm{~m}$ a.s.l. (Fig. 3). Most of the points have slope angles in the range 10-45 . GST and SC also exist in near-vertical conditions and even some BH (Zugspitze (D), Aiguille du Midi (F), Gemsstock (CH), Grawand (IT)) are located in steep rock faces. GP, TR and SM mostly occur on gently inclined slopes. The distribution of slope aspects is slightly biased towards the North $(36 \%)$ and West $(24 \%)$ with fewer points (20\% each) in the South and East. The majority $(85 \%)$ of points have no or only sparse vegetation cover and few have partial or complete coverage (15\%, mostly of type TR). Most (44\%) of the evidence are located in coarse debris, the others are in bedrock (33\%) and in fine material (23\%). Evidently, types such as SC and TR are biased towards a certain surface type. About $20 \%$ of $\mathrm{BH}$ and GST are situated on plateaus or ridges, while $10-15 \%$ of TR are located in depressions. 


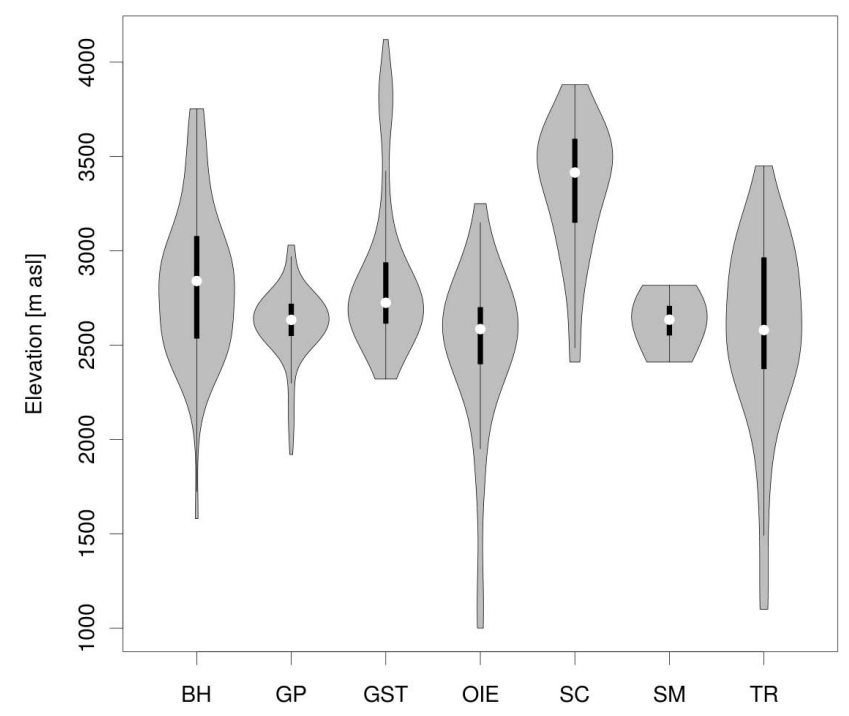

Fig. 3. Elevation range of each type of evidence (except rock glaciers). The plot shown is a combination of a box plot (the white dot is the median, the black boxes range from the lower to upper quartile, and the thin black lines represent the whiskers) and a kernel density plot super-imposed in a mirror image fashion (grey shaded areas).

The depth of BH ranges from 5 to $133 \mathrm{~m}$ with a mean of $33 \mathrm{~m}$. Most boreholes are equipped with temperature sensor chains and data loggers but some require manual measurements. For each BH, active layer depth as well as mean annual ground temperature (MAGT) of the coldest sensor is reported as the mean of all available measurement years. As BH have variable depths, the MAGST of the coldest sensor is used as an indication for permafrost conditions. GST is mostly measured at a depth of around $10 \mathrm{~cm}(55 \%)$, with some measurements being shallower $(25 \%$ at $0-2 \mathrm{~cm})$ and others deeper $(20 \%$ at $15-55 \mathrm{~cm})$. GST is reported as the mean of all full measurement years with durations ranging from 3 to $5 \mathrm{yr}$.

Evidence of the absence of permafrost is also relevant: whilst $75 \%$ of the rock glaciers presented in the inventory are relict forms, only $23 \%$ of the point types of evidence indicate the absence of permafrost. $61 \%$ of point evidence where permafrost absence has been ascertained are ground surface temperature, $17 \%$ are boreholes and $22 \%$ are represented by geophysical investigations and trenches. Points of permafrost absence have a mean elevation of $2600 \mathrm{~m}$ a.s.1. but can reach also elevations higher than $3500 \mathrm{~m}$ a.s.l. in particularly unfavourable conditions (e.g. south exposed rock walls).

\section{Data access}

The October 2010 version of the inventory is available digitally at www.geo.uzh.ch/microsite/cryodata/. A compressed version of the inventory can be downloaded containing point types of evidence in ASCII format. Since the rationale behind the inventory is data sharing, point evidence publication policy are classified in two categories: "Usage without restriction" and "Inform before publication". Data belonging to the first category can be downloaded without any feedback to the owner while in the latter case, an automatic email reporting the contact person and the intended use of the data, will be sent to the owner when a download occurs.

\section{Conclusions}

We have established an inventory of permafrost evidence for the Alps and made its contents freely available to other scientists and practitioners. This inventory complements monitoring programmes in which changes in permafrost terrain are measured at individual locations with great precision and over long time spans (e.g. PERMOS, PermaFRANCE or NorPerm, Juliussen et al., 2010) by providing a solid basis to advance the understanding of the spatial distribution of permafrost and its evolution in heterogeneous mountain environments. While the homogenized contents and public availability of the inventory increase the value of the data contained, the synopsis of data over a larger region additionally enables analyses that were previously not possible, as larger environmental gradients are covered and more data points available. Future experience with data homogenization, scientific analyses, gathering of evidence, re-interpretation of existing data for inclusion in the inventory and with merging differing inventories and monitoring systems into higherlevel products will likely require or inspire changes to the structure and strategy outlined here. In addition, the provision of proper user interfaces for the input, validity checking and output of data as well as strategies to ensure correct scientific governance and data stewardship are important to maximize the acceptance and utility of inventories such as the one presented here.

\section{Appendix A}

\section{Inventory structure}

1. General Information (required for all types of evidence)

- Evidence Type: Borehole (BH), Geophysics (GP), Rock fall scar (SC), Ground surface temperature (GST), Surface movement (SM), Trench or construction site (TR), Other indirect evidence (OIE);

- Country ID: Austria (A), Germany (D), France (F), Italy (I), Switzerland (CH), Liechtenstein (FL), Slovenia (SLO); 
- Evidence ID: progressive code to identify the single evidence;

- Site name: established name for site;

- Responsible name: first and last name of responsible person/data owner. This person is to be contacted for any questions and also for impending publications;

- Responsible email: e-mail address of responsible person/data owner;

- Longitude: coordinates of the evidences (WGS84, decimal degrees);

- Latitude: coordinates of the evidences (WGS84, decimal degrees);

- Coordinate accuracy: approximate accuracy of coordinates $(\mathrm{m})$;

- Position method: method used for locating site (e.g. GPS, MAP, Google Earth, others);

- Orientation method: method used for determining slope and aspect (e.g. field, GIS, other);

- Elevation: elevation of the evidence point (m);

- Slope: slope, expressed in degrees, of the evidence point $\left(^{\circ}\right)$;

- Aspect: aspect, expressed in degrees, of the evidence point $\left(90^{\circ}\right.$ for East, $180^{\circ}$ for South, $270^{\circ}$ for West, $360^{\circ}$ for North);

- Vegetation: degree of vegetation cover: none, sparse, partly covered, complete coverage;

- Surface type: coarse debris (no fines at surface), fine grained debris (fines at surface) or bedrock;

- Permafrost YES/NO: permafrost presence or absence (Yes/No);

- Permafrost certainty: degree of certainty related to permafrost presence or absence: high certainty (i.e.definite proof), medium certainty, low certainty;

- Justification: explanation and justification of the permafrost degree of certainty given;

- Ice: indication of the presence of ice below active layer depth or visible in rock fall scar (Yes/No/Unknown);

- Ice depth: depth of visible ice (m);

- Date last: last observation confirming permafrost state;

- Permafrost comments: any additional comments on permafrost;

- Terrain characteristics: indication of the type of terrain: slope, ridge, peak, plateau, depression, slope base;
- Source type: source of the information related to the evidence: literature, field observation, personal communication;

- Source comment: any additional comment on the source type;

- Publication policy: Usage without restriction, Inform before publication.

2. Additional information (not obligatory)

- Additional data: indication of any additional measurement existing at this site (e.g. snow depth, air temperature, ...);

- Comments general: any other information about the site that may be important;

- Publications: indication of publications where the site and its permafrost condition are discussed (specifically).

3. Boreholes (specific information required for boreholes)

- Borehole name: established local borehole name;

- Borehole depth: maximum depth of the borehole (m);

- Borehole ALT: mean of maximum annual active layer thickness $(\mathrm{m})$;

- Borehole ALT years: years used for the calculation of average active layer depth;

- Borehole MAGT min: minimum mean annual temperature in the borehole (i.e. the mean annual temperature of the coldest sensor) $\left({ }^{\circ} \mathrm{C}\right)$;

- Borehole MAGT min depth: depth of the sensor used for the minimum mean annual temperature (m);

- Borehole MAGT period: years used for the calculation of the minimum mean annual temperature;

- Borehole MAGT accuracy: accuracy of the temperature sensors installed in the borehole;

- Borehole GST: mean annual ground surface temperature; indicates if a measurement is available near the borehole not in the same thermistor chain $\left({ }^{\circ} \mathrm{C}\right)$;

- Borehole comments: any additional information: e.g. borehole with/without tubing, depth of Zeroannual amplitude (ZAA), angle of drilling (relative to ground surface) if borehole is not vertical.

4. Ground Surface Temperatures (specific information required for GST)

- GST mean: mean ground surface temperature $\left({ }^{\circ} \mathrm{C}\right)$;

- GST period: years used for the calculation of the mean ground surface temperature; 
- GST measurement depth: maximum depth of measurement from surface $(\mathrm{cm})$;

- GST accuracy: accuracy of the temperature sensors;

5. Surface Displacement (specific information required for SD)

- Displacement method: indication of the method used to measure displacement: field observation, air photo observation, photogrammetric analysis, terrestrial survey, InSAR, ...;

- Movement rate: $\mathrm{cm} \mathrm{day}^{-1}, \mathrm{~cm} \mathrm{month}^{-1}$ or $\mathrm{cm} \mathrm{yr}^{-1}$;

- Movement date: date of measurement.

6. Rock glacier inventory (required for each rock glacier inventory)

- RGI ID: number of the rock glacier inventory;

- RGI name: name of the inventory;

- RGI file name: filename of the corresponding shapefile;

- RGI coordinate system: coordinate system of the inventory;

- RGI delineation base: specification of the delineation method used (e.g. air photo, map, field observation etc.);

- RGI mapping strategy: specification of the mapping strategy used to compile the inventory (e.g. random sample of rock glaciers/all rock glaciers/only large rock glaciers etc.);

- RGI year: date of the rock glacier inventory;

- RGI responsible name: first and last name of responsible person/data owner;

- RGI responsible email: e-mail address of responsible person/data owner;

- RGI publication: indication of publications where the rock glacier inventory is discussed (specifically).

7. Rock glacier (required for each rock glacier)

- Degree of activity: definition of the degree of activity using two classes: Intact (Active/inactive) or Relict;

- RG field evidence: presence of field evidence for the rock glacier (e.g. Measurements)? Yes/No;

- RG activity data: presence of InSAR (A), geodetic (B), photogrammetric (C), GPS (D) or other (E) data for the rock glacier: no data, activity, no activity;
- RG vegetation front: presence of vegetation on the front of the rock glacier: Yes, No, Unknown;

- RG glacier above: presence of a glacier or perennial snow field in the root zone of the rock glacier: Glacier, Perennial snow field, No.

\section{Appendix B}

\section{List of contributing institutions}

- Austria

1. ZentralAnstalt für Meteorologie und Geodynamik - ZAMG

2. Universität Graz

- France

1. Conservatoire National des Arts et Métiers - CNAM

2. Université Joseph Fourier

3. Université de Savoie

4. Centre national de la recherche scientifique - CNRS

- Germany

1. Bayerisches Landesamt für Umwelt - LfU

- Italy

1. Agenzia Regionale per la Protezione dell'Ambiente del Piemonte - ARPA Piemonte

2. Agenzia Regionale per la Protezione dell'Ambiente della Valle d'Aosta - ARPA VdA

3. Fondazione Montagna Sicura

4. Provincia Autonoma di Bolzano

5. Provincia Autonoma di Trento

6. Regione Veneto

- Switzerland

1. Bundesamt für Umwelt - BAFU

2. Université de Lausanne - UNIL

3. Universität Freiburg

4. WSL Institute for Snow and Avalanche Research - SLF

5. Universität Zürich - UZH 
Acknowledgements. The project PermaNET is part of the European Territorial Cooperation and is co-funded by the European Regional Development Fund (ERDF) in the scope of the Alpine Space Programme (http://www.alpine-space.eu). We are grateful to all data contributors: Broccard A., Crittin C., Curtaz M., Delaloye R., Fabre D., Garcia S., Hölzle M., Keusen H. R., Kroisleitner C., Krysiecki J. M., Lambiel C., Lieb G., Mari S., Monnier S., Paro L., Riedl C., Rovera G., Schoeneich P., Springman S., Walcher J., Zampedri G., as well as the Swiss Permafrost Monitoring Network (PERMOS). Alexander Brenning has contributed to designing the initial structure of the inventory.

Edited by: R. Rigon

\section{References}

Allen, S., Gruber, S., and Owens, I.: Exploring steep bedrock permafrost and its relationship with recent slope failures in the Southern Alps of New Zealand, Permafrost Periglac., 20, 345356, 2009.

Gruber, S. and Hoelzle, M.: Statistical modelling of mountain permafrost distribution: local calibration and incorporation of remotely sensed data, Permafrost Periglac., 12, 69-77, 2001.

Hoelzle, M.: Mapping and modelling of mountain permafrost distribution in the Alps, Norsk Geogr. Tidsskr., 50, 11-15, 1996.

Imhof, M.: Modelling and verification of the permafrost distribution in the Bernese Alps (Western Switzerland), Permafrost Periglac., 7, 267-280, 1996.
Juliussen, H., Christiansen, H. H., Strand, G. S., Iversen, S., Midttømme, K., and Rnning, J. S.: NORPERM, the Norwegian Permafrost Database - a TSP NORWAY IPY legacy, Earth Syst. Sci. Data, 2, 235-246, doi:10.5194/essd-2-235-2010, 2010.

Keller, F.: Automated mapping of mountain permafrost using the program PERMAKART within the geographical information system ARC/INFO, Permafrost Periglac., 3, 133-138, 1992.

Lambiel, C. and Reynard, E.: Regional modelling of present, past and future potential distribution of discontinuous permafrost based on a rock glacier inventory in the Bagnes-Hérémence area (Western Swiss Alps), Norsk. Geogr. Tidsskr., 55, 219-223, 2001.

Mair, V., Zischg, A., Krainer, K., Stötter, J., Zilger, J., Belitz, K., Schenk, A., Damm, B., Kleindienst, H., Bucher, K., Lang, K., Tagnin, S., and Munari, M.: PROALP Rilevamento e monitoraggio dei fenomeni permafrost. Esperienze della Provincia di Bolzano, Neve e Valanghe, 64, 50-59, 2008.

Noetzli, J. and Vonder Muehll, D. (Eds.): PERMOS 2010. Permafrost in Switzerland 2006/2007 and 2007/2008, Glaciological Report Permafrost No. 8/9, Cryospheric Commission of the Swiss Academy of Sciences, 2010.

Schoeneich, P., Bodin, X., Krysiecki, J., Deline, P., and Ravanel, L.: Permafrost in France. Report No. 1, Institute of Alpine Geography, University of Grenoble, 2010. 